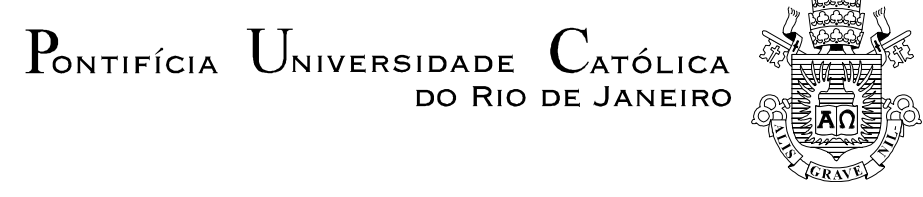

Alexandre Panza Vidal

Avaliação de Projeto de Mineração Aplicando a Teoria de Opções Reais

Dissertação apresentada como requisito parcial para obtenção do título de Mestre pelo Programa de PósGraduação em Administração de Empresas da PUC-Rio.

Orientador: Prof. Luiz Felipe Jacques da Motta Co-Orientador: Prof. Luiz Eduardo Teixeira Brandão

Rio de Janeiro Julho de 2008 


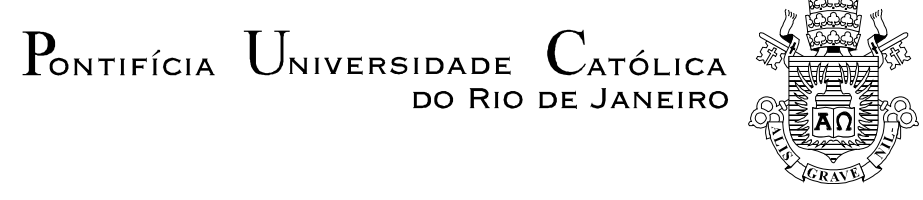

Alexandre Panza Vidal

\title{
Avaliação de Projeto de Mineração Aplicando a Teoria de Opções Reais
}

\begin{abstract}
Dissertação apresentada como requisito parcial para obtenção do título de Mestre pelo Programa de PósGraduação em Administração de Empresas da PUC-Rio. Aprovada pela Comissão Examinadora abaixo assinada.
\end{abstract}

Prof. Luiz Felipe Jacques da Motta Orientador Departamento de Administração - PUC-Rio

Prof. Luiz Eduardo Teixeira Brandão Co-Orientador Departamento de Administração - PUC-Rio

Prof. Marcelo Cabus Klotzle Departamento de Administração - PUC-Rio

Prof. Leonardo Lima Gomes Neoenergia

Prof. Nizar Messari Vice-Decano de Pós-Graduação do CCS 
Todos os direitos reservados. É proibida a reprodução total ou parcial do trabalho sem autorização da universidade, do autor e do orientador.

\section{Alexandre Panza Vidal}

Graduou-se em Engenharia de Produção pela PUC RIO em 2004 e concluiu o mestrado de administração de empresas pela PUC RIO em 2008. Atuou na área de avaliação de negócios e planejamento financeiro em empresas de grande porte, nacional e multinacional. Seus interesses de pesquisa estão relacionados à avaliação de projetos de investimento, planejamento estratégico, avaliação de desempenho corporativo e processos de fusões e aquisições de empresas.

Ficha Catalográfica

Vidal, Alexandre Panza

Avaliação de projeto de mineração aplicando a teoria de opções reais / Alexandre Panza Vidal; orientador: Luiz Felipe Jacques da Motta; co-orientador: Luiz Eduardo Teixeira Brandão. - 2008.

75 f. ; $30 \mathrm{~cm}$

Dissertação (Mestrado em Administração) - Pontifícia Universidade Católica do Rio de Janeiro, Rio de Janeiro, 2008.

Inclui bibliografia

1. Administração - Teses. 2. Opções reais. 3. Análise de projetos. 4. Análise de decisões. I. Motta, Luiz Felipe Jacques da. II. Brandão, Luiz Eduardo Teixeira. III. Pontifícia Universidade Católica do Rio de Janeiro. Departamento de Administração. IV. Título. 


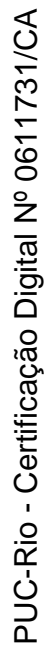

Dedico este trabalho aos meus pais, namorada e irmã, que me deram apoio e incentivo. 


\section{Agradecimentos}

Agradeço ao meu orientador, Professor Luiz Felipe, pela ajuda, contribuições, interesse e apoio para realização deste trabalho.

Agradeço ao Professor Luiz Brandão pela co-orientação e contribuições importantes sobre o tema escolhido.

Agradeço a todos os professores que contribuíram direta e indiretamente ao longo do curso de mestrado.

Agradeço à Marcelle por toda paciência e incentivo. 


\section{Resumo}

Vidal, Alexandre Panza; Motta, Luiz Felipe Jacques da; Brandão, Luiz Eduardo Teixeira. Avaliação de Projeto de Mineração Aplicando a Teoria de Opções Reais. Rio de Janeiro, 2008. 75p. Dissertação de Mestrado - Departamento de Administração, Pontifícia Universidade Católica do Rio de Janeiro.

A demanda por commodities mineral e energético no mundo vem sofrendo um forte aumento nos últimos anos causado principalmente pelo crescimento da economia chinesa. No setor de minério de ferro movimentos de aquisições e consolidações são cada vez mais freqüentes pois grandes grupos siderúrgicos buscam, por meio de aquisições, garantir o fornecimento de seu principal insumo e se proteger contra a forte variação do preço no mercado e, por outro lado, empresas de mineração, ao se consolidarem, se protegem contra essas ameaças. A avaliação de novos projetos de mineração é fundamental para identificar o valor da empresa ao considerarmos que uma empresa de mineração é um portfólio de projetos. Dada as características de alguns projetos de mineração, o uso da Teoria de Opções Reais permite uma avaliação mais eficiente do valor destes projetos em função das flexibilidades gerenciais e incertezas de mercado. Esta dissertação procura rever e aplicar os conceitos de opções reais utilizando a probabilidade neutra ao risco e processo estocástico com drifts de crescimento da variável de incerteza através de um projeto de mineração hipotético com a opção de expandir sua capacidade em um prazo de 5 anos.

\section{Palavras-chave}

Opções Reais; Análise de Projetos; Análise de Decisões 


\section{Abstract}

Vidal, Alexandre Panza; Motta, Luiz Felipe Jacques da; Brandão, Luiz Eduardo Teixeira. Mining Project Valuation Applying The Real Option Theory. Rio de Janeiro, 2008. 75p. MSc. Dissertation - Departamento de Administração, Pontifícia Universidade Católica do Rio de Janeiro.

The world demand for mineral and energetic commodities is rising strongly in the last years due mainly to the growth of the Chinese economy. In the iron ore industry movements of merger and acquisition are more frequent therefore steel producers groups are looking to, by means of acquisition, guarantee their iron ore supply and to protect against the huge volatility of price in the market. On the other hand mining companies are protecting their business against these threats by merger operations. In this context, the valuation of new mining projects is essential to identify the enterprise value, considering that a mining company is a portfolio of projects. Given the characteristics of some mining projects, the use of the Real Option Theory allows a more efficiently valuation be done in presence of flexibilities and market uncertainties. This thesis intent to apply the concepts of real option, considering the risk neutral probability and stochastic process with growth drift of the variable of uncertainty, thru a hypothetic mining project, which holds a capacity expansion option that can be exercised in the five year time.

\section{Keywords}

Real Option; Valuation; Decision Analysis 


\section{Sumário}

1 Introdução 12

1.1. Objetivos 13

1.2. Delimitação do Estudo 14

1.3. Relevância do Estudo 15

1.4. Estrutura da Dissertação 15

2 Referencial Teórico 16

2.1. Modelagem Financeira Tradicional 16

2.1.1. Fluxo de Caixa Descontado 17

2.1.2. Custo de Capital 18

2.2. Teoria das Opções Reais 19

2.2.1. Opções Financeiras 20

2.2.2. Tipos de Opções Reais

2.2.3. Movimento Geométrico Browniano 25

2.2.4. Princípios da Neutralidade ao Risco 26

2.2.5. Modelo Binomial 28

2.2.6. Preço de Mercado do Risco 30

2.2.7. Modelo de Avaliação de Opções Reais 32

2.2.8. Simulação de Monte Carlo 35

3 Mercado de Mineração no Brasil $\quad 37$

$\begin{array}{ll}3.1 . & \text { Histórico } \\ 37\end{array}$

3.2. Condições Atuais de Mercado 38

3.3. Projeto de Mineração 40

3.4. A Teoria de Opções Reais na Avaliação de Ativos de Recursos Naturais 44

4 Aplicação ao Projeto de Expansão de uma Mina 45

4.1. Introdução 45

4.2. Premissas $\quad 45$

4.2.1. Reservas Minerais $\quad 47$

$\begin{array}{lr}\text { 4.2.2. Investimentos } & 47\end{array}$ 
4.2.3. Custo e Despesas 49

4.2.4. Preço do Minério de Ferro 50

4.2.5. Custo de Capital 51

4.3. Modelagem Financeira do Projeto 52

4.4. Flexibilidade do Projeto 54

4.4.1. Opção de Expandir $\quad 54$

4.5. Solução 56

4.5.1. Modelagem Determinística: FCD sem Opção 56

4.5.2. Determinação da Volatilidade 58

4.5.3. Risco do Projeto 61

Árvore de Eventos 63

4.5.5. Opção de Expansão (Árvore de Decisão) 66

5 Conclusões e Recomendações $\quad 70$

5.1. Conclusões 70

5.2. Sugestões para Trabalhos Futuros $\quad 71$

6 Referências Bibliográficas $\quad 73$

$\begin{array}{ll}\text { Anexol } & 75\end{array}$ 


\section{Lista de figuras}

Figura 1 - Quatro Tipos de Opções Reais 22

Figura 2 - Modelo Binomial $\quad 28$

Figura 3 - Resumo do Modelo da Copeland \& Antikarov 32

Figura 4 - Brasil no Ranking Internacional de Produção por Minerais 37

Figura 5 - Relação oferta-demanda de minério de ferro 38

Figura 6 - Curva histórica e esperada de preço FOB Itabira para Europa de finos de minério de ferro (em unidades de Fe seca) 39

Figura 7 - Etapas da Obtenção de Direitos Minerários 41

Figura 8 - Classificação do Minério de Ferro por Produto 43

Figura 9 - Investimento de Recentes Projetos de Minério de Ferro 48

Figura 10 - Referências de custo de produção e transporte até porto de embarque de diferentes projetos de minério de ferro 49

Figura 11 - Obtenção do Custo de Capital 51

Figura 12 - Comportamento do processo estocástico do preço do minério 60

Figura 13 - Valor esperado do projeto 60

Figura 14 - FCD do projeto de mineração à taxa livre de risco 62

Figura 15 - Modelo da árvore binomial do projeto 64

Figura 16 - Árvore de eventos do projeto 65

Figura 17 - Opção de expansão da produção 66

Figura 18 - Árvore de decisão do projeto com opção de expansão 67

Figura 19 - Freqüência da decisão de expandir 68

Figura 20 - Sensibilidade do investimento para expansão do projeto 68

Figura 21 - Sensibilidade da volatilidade do preço do minério 69 


\section{Lista de tabelas}

Tabela 1 - Comparação Opção Financeira x Opção Real 22

Tabela 2 - Premissas adotadas para avaliação do projeto de mineração 46

Tabela 3 - Método de precificação do minério de ferro 50

Tabela 4 - Valores esperados do preço do minério de ferro para cada ano do projeto 51

Tabela 5 - Modelo de fluxo de caixa 53

Tabela 6 - Opção de expansão da mina 56

Tabela 7 - FCD do projeto de mineração em operação 57

Tabela 8 - Preço de histórico do minério de ferro em US\$/dmtu 58

Tabela 9 - Drift variável do preço do minério de ferro no processo estocástico 59 